\title{
EMPATIA NA ASSISTÊNCIA EM ENFERMAGEM SOB A LUZ DE WATSON
}

Resumo: Nesta reflexão traremos a luz o pensamento da téorica Jean Watson, buscando como objetivo, propor uma reflexão teórica sobre empatia na assistência em enfermagem e a Teoria Transpessoal do Cuidado Humano de Watson. Trata-se de uma reflexão a qual se fundamenta na Teoria Transpessoal de Jean Watson e como ela impacta diretamente na prática assistêncial do enfermeiro. É apresentado os dez Processos Caritas, e cada elemento de cuidado proposto na teoria, argumenta-se o valor da empatia na prática diária de enfermagem, torna-se relevante resgatar a valorização de teorias na formação de profissionais da saúde, mesmo após o término da graduação. Percebe-se, que esta reflexão contribui para o debate sobre temas essenciais na formação e na prática de enfermeiros, como as teorias de enfermagem, a empatia e no paciente como centro do cuidado.

Descritores: Empatia, Teoria de Enfermagem; Cuidados de Enfermagem; Assistência Centrada no Paciente.

\section{Empathy in nursing care in the light of Watson}

Abstract: In this reflection we will bring to light the thought of the theoretician Jean Watson, seeking as main objective, to propose a theoretical reflection on empathy in nursing care and the Transpersonal Theory of Human Care by Jean Watson. This is a reflection study which is based on Jean Watson's Transpersonal Theory and how it directly impacts on the nurse's assistance practice. The ten Caritas Processes are presented, and each element of care proposed in theory, argues the value of empathy in daily nursing practice, it becomes relevant to rescue the valorization of theories in the training of health professionals, even after the completion of graduation. It can be seen that this reflection contributes to the debate on essential topics in the training and practice of nurses, such as nursing theories, empathy and the patient as the center of care.

Descriptors: Empathy, Nursing Theory, Nursing Care, Patient-Centered Care.

\section{Empatía en el cuidado de enfermería a la luz de Watson}

Daiane Pereira Alves Acadêmica de Enfermagem do Instituto Brasileiro de Medicina e Reabilitação - IBMR. Rio de Janeiro, RJ, Brasil. E-mail: alves.daiane0@gmail.com

Fernanda Araújo Santos Acadêmica de Enfermagem do Instituto Brasileiro de Medicina e Reabilitação - IBMR. Rio de Janeiro, RJ, Brasil.

E-mail: fernandavdl.santos@gmail.com

Helga Rocha Pitta Portella Figueiredo

Enfermeira. Mestranda da Universidade Federal Fluminense, Escola de Enfermagem Aurora Afonso da Costa, Niterói, RJ, Brasil. Docente do Instituto Brasileiro de Medicina e Reabilitação - IBMR. Rio de Janeiro, RJ, Brasil. E-mail: helgapitta@gmail.com

Claudia Mara de Melo Tavares Enfermeira. Doutora. Professora titular da Universidade Federal Fluminense, Escola de Enfermagem Aurora Afonso da Costa, Niterói, RJ, Brasil. E-mail: claudiamarauff@gmail.com

Submissão: 19/04/2021 Aprovação: 25/10/2021 Publicação: 21/12/2021
Resumen: En esta reflexión, sacaremos a la luz el pensamiento de Jean Watson, que busca proponer una reflexión teórica sobre la empatía en el cuidado de enfermería y la Teoría Transpersonal del Cuidado Humano de Watson. Se trata de una reflexión que se basa en la Teoría Transpersonal de Watson y cómo impacta directamente en la práctica asistencial de la enfermera. Se presentan los diez Procesos Caritas, y cada elemento de cuidado propuesto en teoría, argumenta el valor de la empatía en la práctica diaria de la enfermería, cobra relevancia rescatar la valorización de las teorías en la formación de los profesionales de la salud, incluso después de la finalización de la graduación. Se puede apreciar que esta reflexión contribuye al debate sobre temas esenciales en la formación y práctica del enfermero, como las teorías de enfermería, la empatía y el paciente como centro de atención.

Descriptores: Empatía, Teoría de Enfermería, Cuidado de Enfermera, Atención Centrada en el Paciente. 


\section{Introdução}

No princípio, cada sociedade tinha pessoas que cuidavam umas das outras, tendo a figura da mulher como cuidadora e que tinha como dever zelar pelo bem-estar dos seus entes. A palavra inglesa nurse tem sua origem no latim, do termo nutrix, que significa "mãe que cria". Nesse sentido, há uma ligação histórica entre esse predomínio da mulher com o cuidado, mesmo com o passar do tempo, a enfermagem é uma profissão composta majoritariamente por mulheres ${ }^{1}$.

A enfermagem é considerada como a arte do cuidar e tem se estruturado ao longo de sua trajetória reforçando este perfil, porém, somente traçou-se um longo percurso até que a importância do cuidar ganhasse foco de estudo. O conceito de cuidar nos remete a uma prestação de assistência, tão necessária ao paciente. Esta valorização da assistência está presente nos cursos de formação de enfermeiros, porém os estudantes sentem dificuldade em relacionar a base teórica recebida em sua formação com a necessidade prática em sua futura atuação².

Nos primeiros anos de curso o aluno se depara com o estudo das Teorias de Enfermagem, teorias estas que colocam a Ciência do Cuidado como condição disciplinar as tornando matriz de orientação para o desenvolvimento profissional. Toda profissão exige uma clareza de contexto, desta forma, entendemos que os preceitos teóricos da enfermagem são considerados como âncora para as ações deste profissional. As teorias de enfermagem objetivam e orientam as atividades, para a prestação de uma assistência ética e de qualidade ${ }^{3}$.

Uma das teorias que se destaca no estudo dos futuros profissionais de enfermagem, é a Teoria
Transpessoal, que nasce através de estudos realizados por Margaret Jean Harman Watson. A autora defende em sua teoria a importância do relacionamento e do cuidado humano. Reconhecida mundialmente pelo seu trabalho a teórica orienta que o cuidado prestado de forma humanizada faz toda diferença tanto para quem recebe como para quem presta o cuidado.

Por certo, cuidar de forma humanizada é valorizar os sujeitos, oportunizando maior autonomia e compartilhando o cuidado, para tal é necessário que se crie uma relação com estes, e a empatia surge como condição básica para um relacionamento de ajuda e de cuidado. Neste relacionamento há aspectos básicos indispensáveis para tornar terapêutico este processo, entre estes a empatia. A palavra empatia tem como seu significado, a importância do sentimento de importar-se com o outro a ponto de se colocar no lugar sem fazer julgamentos ou repreensões, é a forma expandida da compreensão de ser e estar. O impacto que essa ação tem na vida de uma pessoa é notada no próprio semblante do paciente, e na satisfação encontrada dentro de cada profissional que coloca em prática essa palavra. Se este profissional desejar que, na sua interação com o paciente, as relações tornem-se realmente terapêuticas, ele deve tentar sentir a experiência deste, tal como ele a percebe o olhar diferenciado ao próximo é o que distingue a prestação do cuidar ${ }^{4}$.

\section{Objetivo}

Propor uma reflexão teórica sobre empatia na assistência de enfermagem, sob a luz da Teoria Transpessoal do Cuidado Humano de Jean Watson.

\section{Material e Método}

Trata-se de um estudo de reflexão o qual se fundamenta na Teoria Transpessoal de Jean Watson e 
como ela impacta diretamente na prática assistencial do enfermeiro, além da percepção das autoras a respeito do assunto abordado. Buscou-se discutir estudos no campo da enfermagem que debatessem sobre a temática, assim como obras de domínio público de Watson, a fim de compreender melhor sobre sua teoria e a correlação com a empatia bem como seu impacto na assistência de enfermagem.

\section{Desenvolvimento}

O cuidar é traduzido para Watson como uma forma de ser em que o enfermeiro dá algo de si e recebe algo em troca. 0 ser humano deseja estar em comunhão, mas ao mesmo tempo deseja ser único, tanto o paciente quanto o enfermeiro têm um objetivo ou expectativa em mente ${ }^{1}$. O cuidado exerce um papel fundamental no exercício da profissão, um enfermeiro sem uma consciência cuidadora, pode na verdade causar um descuidado, sendo prejudicial a experiência do outro 4 .

Por outro lado, um enfermeiro que está cultivando uma relação de empatia, ou seja, doação e recebimento de vida para si e para o outro e, portanto, é mais provável que se envolva e experimente um momento de cura e cuidado transpessoal. À medida que o profissional cultiva essas habilidades, sensibilidades de cuidar, há um convite à abertura para processos de cura interior que se expandem para novas possibilidades ${ }^{3}$.

À medida que a enfermagem afirma de forma mais pública e profissional essas posições a partir de um contexto da ciência do cuidado para suas teorias, ética e práticas, somos convidados a realocar a nós mesmos e nossa profissão para longe da mentalidade dominante da ciência médica. Além disso, somos solicitados a reconectar a fonte disciplinar da enfermagem à sua nobre herança, do cuidado universal e do amor. Essa ideia desperta um senso de reverência em relação a nosso trabalho, nossa vida e todas as coisas vivas. Ela incorpora arte, ciência e espiritualidade à medida que são redefinidas ${ }^{3}$.

A teoria transpessoal traz uma ressignificação do cuidado humano. Margaret Jean Harman Watson, é a responsável por desenvolvê-la durante seus estudos no doutorado na Escola de Enfermagem da Universidade do Colorado, entre 1975 e 1979. Ademais, suas pesquisas deram origem ao livro "The Philosophy and Science of Caring", publicado em 1979, que demonstrou mundialmente a importância no cuidado humano e abriu portas para novas descobertas ${ }^{5}$. Em 1985, a teoria sofreu alterações, bem como a redefinição de conceitos utilizados pela autora.

\section{Reflexões acerca do cuidado}

O termo Caritas, deriva da origem latina que significa "cuidar, apreciar, dar atenção especial, se não amorosa". Os fatores Carativos, aplicados na teoria transpessoal, são descritos como processos fundamentais da relação de humano para humano. Posteriormente, os "Fatores carativos", passaram a ser designados como "Processos Caritas".

Para a teórica, na relação de cuidado pessoal/profissional, cultiva-se uma aceitação, compaixão e misericórdia como parte da condição humana. Este nível de consciência é para entrar e sustentar o cuidado profissional na enfermagem, ao mesmo tempo em que honra a nossa humanidade profunda, está fundamentado em um modelo muito diferente dos rotineiramente utilizados pela enfermagem e pela medicina convencionais ${ }^{3}$. 
Para melhor elucidar sobre o exposto sobre a teoria de Watson, apresentaremos abaixo uma tabela com a atualização baseada no material do texto de
1979 e demonstrando a evolução do dos dez Fatores Carativos para dez Processos Caritas.

Tabela 1. Correlação entre fatores carativos e processos caritas.

\begin{tabular}{|c|c|}
\hline Fatores carativos & Processos Caritas \\
\hline 1. Valores humanístico-altruístas & $\begin{array}{l}\text { 1. Praticar bondade amorosa e equanimidade para si mesmo e para os } \\
\text { outros }\end{array}$ \\
\hline 2. Incutir / capacitar fé e esperança & $\begin{array}{l}\text { 2. Estar autenticamente presente; habilitar / sustentar / honrar o sistema } \\
\text { de crenças profundo e o mundo subjetivo de si / outro }\end{array}$ \\
\hline $\begin{array}{l}\text { 3. Cultivar sensibilidade para si } \\
\text { mesmo e para os outros }\end{array}$ & $\begin{array}{l}\text { 3. Cultivar as próprias práticas espirituais; aprofundando a } \\
\text { autoconsciência, indo além do "ego-self" }\end{array}$ \\
\hline $\begin{array}{l}\text { 4. Desenvolvendo uma relação de } \\
\text { ajuda, confiança e cuidado humano }\end{array}$ & $\begin{array}{l}\text { 4. Desenvolver e manter uma relação de ajuda, confiança e cuidado } \\
\text { autêntico }\end{array}$ \\
\hline $\begin{array}{l}\text { 5. Promover e aceitar a expressão de } \\
\text { sentimentos positivos e negativos }\end{array}$ & $\begin{array}{l}\text { 5. Estar presente e apoiar a expressão de sentimentos positivos e } \\
\text { negativos como uma conexão com o espírito mais profundo de si e } \\
\text { daquele que está sendo cuidado }\end{array}$ \\
\hline $\begin{array}{l}\text { 6. Uso sistemático de processos } \\
\text { científicos (criativos) de resolução } \\
\text { de problemas }\end{array}$ & $\begin{array}{l}\text { 6. Uso criativo de si mesmo e de todas as formas de saber / ser / fazer } \\
\text { como parte do processo de cuidar (engajar-se na arte das práticas de } \\
\text { cuidar e curar) }\end{array}$ \\
\hline $\begin{array}{l}\text { 7. Promover o ensino-aprendizagem } \\
\text { transpessoal }\end{array}$ & $\begin{array}{l}\text { 7. Envolver-se em experiências genuínas de ensino-aprendizagem dentro } \\
\text { do contexto da relação de cuidado - atender à pessoa inteira e ao } \\
\text { significado subjetivo; tentar permanecer dentro da estrutura de } \\
\text { referência dos outros (evoluir para o papel de "coaching" vs. transmissão } \\
\text { convencional de informações) }\end{array}$ \\
\hline $\begin{array}{l}\text { 8. Proporcionar um ambiente de } \\
\text { apoio, proteção e / ou corretivo, } \\
\text { social e espiritual }\end{array}$ & $\begin{array}{l}\text { 8. Criação de um ambiente de cura em todos os níveis (físico, não físico, } \\
\text { ambiente sutil de energia e consciência por meio do qual a totalidade, a } \\
\text { beleza, o conforto, a dignidade e a paz são potencializadas (Ser / Tornar- } \\
\text { se o ambiente) }\end{array}$ \\
\hline $\begin{array}{l}\text { 9. Auxiliar na satisfação das } \\
\text { necessidades humanas }\end{array}$ & $\begin{array}{l}\text { 9. Reverencial e respeitosamente ajudando nas necessidades básicas; } \\
\text { manter uma consciência intencional e cuidadosa de tocar e trabalhar com } \\
\text { o espírito corporificado de outra pessoa, honrando a unidade do Ser; } \\
\text { permitindo a conexão plena do espírito }\end{array}$ \\
\hline $\begin{array}{l}\text { 10. Permitindo dimensões } \\
\text { fenomenológicas existenciais }\end{array}$ & $\begin{array}{l}\text { 10. Abrindo e atendendo a dimensões existenciais misteriosas, espirituais } \\
\text { e desconhecidas de vida-morte-sofrimento; permitindo um milagre" }\end{array}$ \\
\hline
\end{tabular}

Fonte: Elaborado pelas autoras, 2020.

A tabela apresenta a mudança da terminologia usada pela autora, Processos Caritas é um reconhecimento de uma forma profunda de enfermagem, todos os dez processos possuem ligação direta com a empatia ${ }^{3}$.

O Processo 1, discorre sobre a prática da bondade, em que no cuidado a expressão dos sentimentos é a forma de construir a empatia e o respeito mútuo. Quando o amor se move através de nós, ele inspira tudo o que fazemos. O amor e a compaixão devem começar com a bondade para conosco. Um dos maiores obstáculos para a bondade amorosa é nosso próprio sentimento de indignidade ${ }^{6}$.

É irônico que a educação e a prática de enfermagem exijam tantos conhecimentos diversos e habilidade para fazer o trabalho, mas muito pouco esforço é direcionado para o desenvolvimento de como estar enquanto fazem 0 trabalho. Os 
enfermeiros, muitas vezes, ficam angustiados e desgastados por tentar sempre cuidar, dar e estar ao lado dos outros, sem dar atenção ao cuidado amoroso necessário para si mesmo. Esse modelo convida, senão exige, o enfermeiro a se dedicar ao autocuidado e a práticas que auxiliem na própria evolução da consciência para buscar suas próprias realizações pessoais $^{3}$.

Processo 2, dar atenção emocional, mudar a postura de respostas prontas e prontamente formuladas, o indivíduo é um ser único é como tal possui experiências e vivências diferentes, respeitar a origem e crença de cada um demonstra respeito e dignidade pela pessoa assistida. Esse mecanicismo vai na contramão do que é defendido pelo educador Paulo Freire que dá como dica para um bom diálogo, a importância de se escutar o outro, pois é se escutando que se aprender a falar de igual para igual e assim se fazer compreendido e alcançar êxito no objetivo do cuidar $^{7,10}$.

Processo 3 traz à discussão que muitas pessoas não realizam seu potencial. Eles tendem a procurar soluções fora de si mesmos. Mas a fonte de maturidade, sabedoria, reflexão, percepção e atenção plena para desenvolver uma consciência evoluída está dentro de $\mathrm{si}^{3}$. O autoconhecimento é o que faz o enfermeiro colocar-se no lugar do paciente para aplicar o Processo Caritas. Por outro lado, se um enfermeiro não é sensível a seus próprios sentimentos, é difícil ser sensível ao de outra pessoa. Como resultado, quando isso ocorre, o enfermeiro frequentemente forma relacionamentos profissionais distantes, camuflando conflitos em potencial e até mesmo contribuindo para uma situação tóxica, um ambiente de trabalho insalubre ou mesmo o descuidado com o paciente. ${ }^{3}$

A relação de confiança deve ser conquistada pelo profissional. No Processo 4 compreendemos que isso levará também a uma aproximação com os familiares do paciente. Outro ponto importante é a valorização da linguagem corporal juntamente com a comunicação verbal como essencial para um verdadeiro relacionamento de ajuda' as palavras devem ser escolhidas com cuidado levando em conta o contato visual, por ser um encontro sem palavras. Ao trazer amor e cuidado juntos, aprofunda-se o cuidado transpessoal ${ }^{8,9}$.

A comunicação debatida no Processo 5, é a forma que o profissional tem para se aproximar e interagir com o paciente é neste momento que se torna possível conhecer e estabelecer vínculos, uma relação de ajuda-confiança que favorece a expressão de sentimentos positivos e negativos. O cuidado não pode ser realizado sem estabelecer estas relações como atos contínuos e dinâmicos ${ }^{8}$. Permitindo e facilitando sua expressão, o enfermeiro está contribuindo para o processo de honrar e aceitar os próprios sentimentos, enquanto também cria uma consciência pela qual os sentimentos são capazes de se mover através do indivíduo para serem liberados de forma construtiva. A expressão de sentimentos é um ato de cura em si. Por certo, sem comunicação o ato de cuidar não é realizado ${ }^{3}$.

Certamente, o investimento de instituições de ensino que incentive práticas ativas e realísticas, cria no profissional maneiras de engajar-se em processos criativos na arte de cuidar, ideia defendida pelo processo 6 da teoria de Watson. Porém além de da necessidade de novos profissionais crítico, refletimos 
e criativos, se faz necessário compreender que aprender é um processo que envolve um relacionamento significativo e de confiança, sobre isto trata o 70 processo. O processo de ensino genuíno torna-se transpessoal, na medida em que a experiência, o relacionamento e o significado e importância da experiência afetam ambas as partes no encontro de instruir ${ }^{3}$.

Os processos 8 e 9, estão relacionados à promoção do equilíbrio no ambiente e auxílio para manutenção das necessidades humanas básicas, respectivamente ${ }^{10}$. O paciente quer ser visto como um ser humano único, isso dá ao paciente a sensação de ser alguém especial, significa ser reconhecido como pessoa e ele recebe a confirmação existencial quando chamado pelo próprio nome ${ }^{1}$. Dessa forma, o indivíduo se torna o centro do processo de cuidado. Neste modelo de Enfermagem Caritas, explicita-se que ao tocar outra pessoa, você não está tocando apenas o corpo físico, mas também o espírito encarnado. $\mathrm{Na}$ verdade, "quando uma enfermeira toca outra pessoa, ela ou ele está tocando não apenas o corpo, mas também a mente do outro, o coração do outro e a alma do outro, a própria fonte de vida do outro" ${ }^{3}$.

Por fim no último processo de Caritas, 10, ele alinha a enfermagem e sua missão autêntica de cura da saúde com uma causa humanitária e espiritual mais profunda; essa causa tem a ver com ajudar a sustentar a própria humanidade, contribuindo para a evolução da espécie humana em direção a seres mais espirituais conectados com o campo infinito do amor universal. Este processo traz reflexões acerca da vida, morte e espiritualidade. A importância de perceber o enfermeiro como um suporte no processo, mesmo na morte se descobre o caminho do cuidado autêntico, para com o paciente e familiares ${ }^{7}$.

\section{Reflexão acerca da empatia no cuidado}

A discussão sobre a empatia vem ganhando destaque nos últimos tempos principalmente quando pensamos em toda a situação de calamidade que os profissionais de saúde vêm passando diante da epidemia do COVID 19. O termo passou a ser debatido e defendido com vigor. A cobrança por uma atuação do enfermeiro baseada nas relações empáticas vem sendo muito apontada pela sociedade, mas por vezes esses profissionais se encontram diante de barreiras que dificultam o cuidado, longas jornadas; duplo vínculos empregatícios; múltiplas tarefas geram esgotamento profissional, situações que agregam na dificuldade da projeção de um olhar humanizado e holístico.

Somada a estes fatores, ainda nos deparamos com obstáculos existentes dentro das organizações, decorrentes de estruturas curriculares e pedagógicas educacionais fragilizadas carentes de valorização e implementação da prática profissional orientada pela teoria do cuidado transpessoal. ${ }^{8}$ Os dez fatores acima descritos, foram desenvolvidos através de conhecimentos e pesquisas científicas, sua base é a reciprocidade que deve haver entre enfermeiro e paciente. A autora da teoria, mostra preocupação constante com seu trabalho, fato que se justifica pelo aprimoramento e atualização periódica que realiza em seus escritos. A teoria baseada no cuidado transpessoal orienta e capacita o profissional a ter uma visão panorâmica das dificuldades do paciente, ao valorizar o outro e a estimular a equipe para uma mudança efetiva no cuidado integral ${ }^{2,9}$. 


\section{Conclusão}

A teoria transpessoal traz à tona a importância da relação empática do enfermeiro com o indivíduo ao qual se está ofertando o cuidado, assim como a necessidade de valorização de seus sentimentos e particularidades, seja ele paciente ou membro de sua equipe de trabalho. Está debate ainda sobre o enfermeiro conhecer a si mesmo e compreender suas emoções para ser mais aberto a conhecer o outro.

É destacável que além do ensino da empatia, é necessário o ensino de sua prática. Devendo esta temática ser introduzida no início da formação acadêmica, assim como a consolidação do debate sobre os teóricos de enfermagem visando a formação profissionais que percebam que sua interação se dará com o outro e não com a enfermidade.

Por certo, esse campo precisa ser explorado por futuros profissionais e educadores em saúde e entende-se que essa reflexão pode contribuir no debate sobre a empatia e o cuidado humano, sob a forma como enxergamos o paciente e como transmitimos essas emoções, diferenciando o como de cuidar.

\section{Referências}

1. Holopainen G, Lisbe. N, Anne K. The Caring encounter in nursing. Nursing Ethics. 2019; 26(1):7-16.

2. Kalfoss $M$, Owe Cand, J. building knowledge: the concept of care. Open Journal of Nursing. 2016; 6:9951011.

3. Watson, J. Nursing the philosophy and science of caring. Colorado: University Press Of Colorado. 2008.

4. Figueiredo HRPP, Tavares CMM. How to teach empathy to future nurses? An integrative literature review. Research, Society Development. 2020. 9(9):E463997439.

5. Alligood MR Nursing theorists and their work. 8 . Ed. St. Louis, Missouri: Elsevier. 2013.

6. Kornfield J. The art of forgiveness, lovingkindness, and peace. New York: Bantam. 2002.

7. Perdomo CAR, Vélez MER, Romero AYP. El Consuelo De María: una enseñanza de cuidado desde la teoría de Watson. Index Enferm. 2016; 25(1-2):2732.

8. Costa J R, Marcon SS, Testón EF, Arruda GO, Peruzzo HE, Cecilio HPM, et al. O cuidado no cotidiano hospitalar: perspectivas de profissionais gerentes e assistenciais de enfermagem. Fortaleza: Rev Rene. 2020; 21:1-10.

9. Favero L, Pagliuca LMF, Lacerda MR, Cuidado transpessoal em enfermagem: uma análise pautada em modelo conceitual. Rev Esc Enferm USP. 2013; 47(2):500-505.

10. Freire P. Pedagogia da autonomia: saberes necessários à prática educativa. Rio de Janeiro: Paz e Terra. 1997. 